\title{
The Teach-to-the-Test Approach: A Curse a Blessing or a Blessing in Disguise for Algerian EFL Students
}

\author{
Nabil Djawad Benmoussat ${ }^{1} \&$ Smail Benmoussat ${ }^{1}$ \\ ${ }^{1}$ Faculty of Letters and Languages, ESPT Laboratory, Department of English, University of Tlemcen, Algeria \\ Correspondence: Smail Benmoussat, Faculty of Letters and Languages, Department of English, University of \\ Tlemcen, B P 119, Tlemcen Algeria.
}

Received: June 24, 2018 Accepted: July 27, 2018 Online Published: August 22, 2018

doi:10.5539/ells.v8n3p1 URL: https://doi.org/10.5539/ells.v8n3p1

\begin{abstract}
The present paper is an attempt to redraw the boundaries of EFL from a teaching-testing perspective. Though the crux of the problem in language teaching has always been the general principles underpinning the methodologies, the 'what-to-teach' and the 'what-to-test' questions have always been a concern for most stakeholders. Parents would most probably argue about what is best to be taught to their children as well as about the most appropriate and effective learning path leading to their offspring success, whereas the others, not least, teachers, strive to cope with a delicate intertwined questioning of how to strike the balance between an effective teaching and an efficient testing. However, this thorny issue, so to speak, is not a new one. The relationship between teaching and testing has called into question the communicative abilities of Algerian EFL learners. To score high, through a test-oriented teaching in an EFL exam does not necessarily mean to speak fluently and to write accurately the English language. EFL learners in public schools are in most need of a well-rounded education.
\end{abstract}

Keywords: English language education, what-to-teach, what-to-test, high-stakes exam, teach-to-the-test approach

\section{Introduction}

Today's globalized world is witnessing a growing and a relentless demand for education, and the field of language learning, not least ESL and EFL, is no exception. This remarkable demand, a striking aspect of the post-war period, is due to the paramount role which education plays in affording societies with functional and responsible citizens who, in turn, are expected to contribute positively and significantly to the development of their nations and to meet the requirements of an ever increasing process, globalization. Bolitho (2012, p. 35) contends that "In educating the citizens of tomorrow, we are told, we should be preparing them to cope with change in our increasingly globalised world". Undeniably, education is becoming a key factor in the development of the nations at a global scale, in this sense, quality of education has become imperative to give way to the notion of 'high-quality education' (Note 1) which will motivate and inspire lifelong learning beyond the school gates. This new $21^{\text {st }}$ century-vision of education, with teacher effectiveness as a key component and learner involvement as an active partner, would lead to reconsider and redraw the boundaries of language teaching and language testing within the construct of the communicative abilities of EFL learners in the Algerian state-run schools.

The changes that English Language Education has witnessed, from a teacher-centred pedagogy to a more learner-centred education, from a textbook-based teaching to a task-based approach, from a summative assessment to a formative assessment (Ko, 2000), reflect educators commitment and teachers concern in an effort to find an appropriate methodology which best relates teaching to testing on a communicative continuum. Yet the problematic has not yet been resolved even after decades of continual change, update, and improvement of the English Language Teaching Methodologies. Even worse, the issue has reached a critical state when the main concern of both parents and the educational institution is shifting from students' potential and academic development to students' achievement in exams. In this sense, the word 'achievement' means nothing more than scoring well on standardized tests (Note 2) and high-stakes exams (Note 3) such as the Baccalaureate exam which is a high-stakes test par excellence with too much importance attached to the outcomes. 


\section{Baccalaureate Exam}

\subsection{The Bac: A high-States Exam}

The Baccalaureate, commonly known in Algeria and in many French former colonies under its back-clipped form of ' $L e B A C$ ', is, essentially, a high-stakes secondary school-leaving examination. It allows third-year Secondary Education students to embark on tertiary studies, i.e. an entrance-like visa to university and higher education institutes. Much like British A-Levels or American high school diplomas, the Baccalaureate allows Algerian and international students to obtain a standardized qualification, typically at the age of 18 . From an elitist viewpoint, the Baccalaureate is supposed to act as a roadblock to mediocrity and is employed as a selection instrument for tertiary education.

\subsection{The Bac: An achievement Test}

The Baccalaureate examination, as an achievement test, plays an important role in the Algerian education system at large. It usually takes place in June. This end-of-year period is a very stressful for stakeholders, mainly students, teachers, school administrators and parents. The following are Karima's felt and expressed impressions:

I'm among those students who will sit for the BAC, 2018 session. The closer we get, the higher the tension is. For me the most important thing is to get myself well-organized in always setting a revision planning. I often start my revision by the subject matters that have a higher coefficient. I try to rest every 45 minutes as it is difficult for the human brain to keep focused for a long time. At times, I avoid thinking about the BAC day because of the stress that is always accompanying me (Authors' translation).

Since its inception in 1963, the Baccalaureate examination has always been a lever for change (Note 4) to initiate educational reforms in an effort to establish academic standards and a more or less reliable source of information on educational outcomes to external stakeholders. Its preparation starts early in the school year, sometimes even a few years beforehand. It has a reputation for being a thorough summative assessment. The following table illustrates the fluctuation in the rate of success:

Table 1. Fluctuations in rates of success in baccalaureate exam

\begin{tabular}{lllll}
\hline Academic Year & 2014 & 2015 & 2016 & 2017 \\
\hline Number of Candidates & 657.026 & 623,247 & 818,515 & 761,701 \\
Number of Bac Holders & 316.212 & 320,072 & 396,264 & 395,853 \\
Rate of Success & $45.01 \%$ & $51.36 \%$ & $46.76 \%$ & $51.07 \%$ \\
\hline
\end{tabular}

Source: ONS, Oct. 2017.

\section{The Teach-to-the-Test Approach}

\subsection{Defining an Approach}

The over importance assigned to the bureaucratic nature of the Baccalaureate in the Algerian education system has paved the way for the emergence of a new philosophy. This philosophical conception is rendering teachers even more cynical about the rate of success in the Baccalaureate exam, and devising ways of turning it to productive account for teachers and learners. This cynical dimension would lead us to touch on another aspect of the teach-to-the-test approach: the coaching services that are offered outside school time and school walls by teachers. These so-called extra remedial lessons, oriented chiefly towards practicing exam techniques have turned to become commonplace and a very trendy form of outside-schooling. Students spend evenings, weekends, and even holidays preparing for the Baccalaureate exam in teachers' homes, or even in garages. The following quotation illustrates clearly the rationale, so to speak, underlying such tendency, The benefits of such a compensatory teaching are wide-range: the number of students is very limited, the teacher explains every single word or structure in Arabic or in French, he goes through the exercises that were done in the classroom and the pupil has all the chances to succeed. That's an extra to teachers to make ends meet. It goes without saying that this type of supplementary education costs a great deal of money, and yet students' families willingly or unwillingly try to 'keep up with the Joneses', to use an appropriate idiomatic expression.

\subsection{Test-Oriented Teaching}

On the other hand, most teachers report that they try to follow the textbook only during the first two terms of the year, and many schools stop giving courses and classroom dissolved right before the spring holidays so that students can study on their own. However, in some schools the third term is devoted to a greater use of past papers 
and commercial exam-related publications. This raises the issue why teachers at this period of the year rely extensively on exam-oriented materials and past papers. As Spratt $(2005$, p. 12) notes, "they [teachers] wish to fulfil student expectations or their presumed expectations."This test-oriented teaching is manifested by the students' insistence on doing practice tests. Teachers do this as "they believe the best way to prepare students for exams is by doing past papers" (Lam, 1994, p. 91). This teaching-to-the-test approach, based on Underhill's preach "As ye teach, so shall ye test' (1982, p. 18), has led to the publication and proliferation, on a large scale, of annals containing materials that are highly exam-technique oriented.

Yet, from an educational standpoint, it is believed that this pedagogical approach encourages teachers to focus much more on individual language items and grammar structures rather than engage students in an integrated cyclical learning process. In this way, the textbook becomes a test-book and therefore loses not only its intrinsic value but also many of the attributes which have been assigned to it. This 'unhealthy' and 'unethical' and counter-productive teaching has led to the implementation of the principles of the teach-to-the-test approach (Note 5) forcing, in one way or another, teachers to focus their time, effort and energy on preparing learners for tests in order to raise test scores.

\subsection{Testing: A Necessary Evil}

To better understand what is actually wrong with the teach-to-the-test approach, one needs to dig deeper in order to realize how the relationship between teaching and testing ought to be. No one would deny the fact that testing is a vital component of any instructional programme throughout the world; it has always been viewed and labelled as a 'necessary evil', yet as a means to promote and assess learning. This paradoxical assertion would lead us to state unambiguously that teaching and testing are closely interrelated and complete each other in the sense that there is no testing without teaching nor is there teaching without testing. In an analogical way, they are two facets of the same coin. However, the increasing focus on exam performance has accentuated the pressure on teachers and geared them towards a selective-focussing teaching and caused them to do deliberately great harm to the broader learning process.

However, to function properly, a test is supposed to assess the teaching/learning process at large; narrowly speaking, it is bound to provide a way to measure students' demonstration of learning, qualitatively, i.e. how well and quantitatively, i.e. how much. In very practical terms, a test helps answer a triadic-oriented question: How much did the students learn? How well did they learn it? And, how well did we teach it? In this sense, the test should reflect what was taught in order to be a reliable and a valid one. To meet these goals, teachers need to be familiar with the general guidelines and have a sound knowledge of the key concepts underpinning the different test-types. Such familiarity and mastery will serve as a platform, or rather a springboard for teachers, especially novice and less experienced, to devise a practical test which can be relied on so as to yield valid indices about the learning progress as well as the teaching process.

\section{Teachers' Play Safe Policy}

Arguably, if the interplay between teaching and testing follows a logical sequence based on the teaching of what will be tested, or more precisely, a selective focussing on the teaching items of the test, the cause and effect relationship resulting from the two processes will cause considerable harm to the learning process as a whole. A test cannot cover all items that are prescribed in the curriculum, in this sense, what will not be in the test will not be taught, or at least will not be given much importance or eventually put apart. Hence, a domino-like effect arises: the test will lose its validity; the teaching will lose its credibility and the curriculum will lose its intrinsic value. Yet, But why do teachers are at times bound to follow the teach-to-the-test approach? It is important to know that teachers' conviction to use this approach is due to two main reasons: one pedagogical and the other societal. The pedagogical dimension closely relates to the fact that virtually all teachers point out the overloaded curricula for which they are bound to cover in due time.

\subsection{High Score: Achievement}

This time constraint leads teachers to engage in a selection of only those items that likely to feature prominently in exams rather than to teach effectively and with pace according to their learners degree of intake and assimilation. The societal dimension is due to the fact that both parents and the academic institution give too much importance and great value to the result obtained by their students. In other words, and in terms of accountability, the education institution in general and teachers in particular are judged in relation to their students' success and achievement in exams, not least high-stakes exams, such as the Baccalaureate exam. Since independence in the early 1960s, scores obtained in standardized tests have served as a 'benchmark' to compare and rank educational institutions throughout the country. In sum then, standardized testing is still regarded as a large-scale measure of schools effectiveness. 
In a play-safe policy and, paradoxically, in an effort to satisfy the learners' parents' wants and wishes and to abide by loyally the education institution's rules of the game, the teachers, caught between the hammer and the anvil, have generally recourse to the teach-to-the-test approach. This teaching practice is acknowledged to negatively impact the teaching/learning process, and in consequence, calls into question the credibility of the educational system as a whole. A focus on the quality of education is as crucial as ever, with tests levers for change. What is more, most educators and linguists agree that at present tests are no more testing learners' knowledge and potentials, but testing their ability to reproduce fixed bodies and exact structures of knowledge (Schweisfurth, 2011). As a result, schools are no more those educational institutions with sole attributes encouraging meritocracy and scholastic advancement for those highly motivated and talented students. Even worse, many individual learners, without learning opportunities, cannot develop the competencies and skills that will help them use the language communicatively. Regretfully, one might say that testing, which ought to be the pedagogical tool to assess and promote learning, has lost its intrinsic value and acts as an overt deteriorating element in a teaching approach.

\subsection{Learning English: Pass Exams}

The teaching-to-the-test approach has now become commonplace and its alarming wide spread use has touched many educational institutions worldwide, and the Algeria education system is no exception. The major goal underpinning English teaching in Algeria is to make learners able to communicate, express their ideas, argue, maintain discussions and avoid discussion breakdowns. Yet, sometimes, what is prescribed as objectives and goals is just ink on paper. Unfortunately, at present time, the immediate goal and the principle motivating drive pupils to learn English is to pass examination. This shift in interest has led to the emergence of successful learners on exam seats but ineffective and very incompetent ones in real life context. Moreover, the success of learners in high-stakes exams, such as the Baccalaureate exam, will afford them an opportunity to enter university and embark on a higher education. As an immediate deleterious result, EFL teachers at university level will find themselves facing students who only excel in reproducing faithfully exact forms of knowledge in exam seats rather than having considerable skills in dealing with the language communicatively.

\section{Conclusion}

Arguably, between the demands for high-quality education and the many issues of how to teach effectively and how to test efficiently, a radical change is indeed a necessary step to take further. However, up to there, teachers need to adopt remedial approaches in an effort to make up for the damages resulting from an over use of the-teach-to-the-test approach. University teachers, for instance, need to rethink about reassessing their students to know their students' true colours in terms of language background; they also need to redraw the frames of their lectures to compensate for their learners weaknesses, and ultimately devise new ways for assessing their new acquired knowledge using more attractive alternative assessment procedures such as project-based learning and portfolios (Note 6). This challenging situation is of paramount importance if an education of high quality is to be reached, and the washback (Note 7) effect of the teaching-to-the-test approach to be reduced. However, there is no good news on the horizon.

\section{References}

Alderson, J. C. (2004). Foreword. L. Cheng, Y. Watanabe, \& A. Curtis (Eds.).

Benmoussat, S. (2003).Mediating Language and Culture: An Investigative Analysis of the Cultural Dimension in the Algerian Newly-Designed ELT Textbook. Unpublished Doctorat d'Etat Thesis, Abou Bakr Belkaid University, Tlemcen.

Benmoussat, S., \& Benmoussat, N. D. (2018). The Teach-to-the-Test Approach: Doing Harm to the Lifelong Learning Paradigm of Algerian EFL Learners. English Language, Literature \& Culture, 3(1), 1-6.

Bolitho, R. (2012). Projects and Programmes: Contemporary Experience in ELT Change Management. In N. H. Hornberger (Ed.), Encyclopedia of Language and Education (2nd ed.). Springer.

Cortazzi, M., \& Jin, L. (1999). Cultural Mirrors: Material and Methods in the EFL Classroom. In E. Hinkel (Ed.), Culture in Second Language Teaching and Learning. Cambridge: Cambridge University Press.

Green, T. (1980). Predicting the Behavior of the Education System. Syrawse MY: Syrawse University Press.

Javanmard, Y., \& Farahani, H. (2012). Investigating Using Portfolio Assessment and Learning English Language in Qum Secondary Schools. Global Journal of Human Social Sciences, 12. 
Ko, P. Y. (2000). From Enthusiasm to Caution. In B. Adanson, T. Kwan, \& K. K. Chan (Eds.), Changing the curriculum: The impact of Reform on Primary Schooling in Honk Kong. Honk Kong: Honk Kong University Press.

Lam, H. P. (1994). Methodology Washback: An Insider's View. Bringing About Change in Language Education. Honk Kong: University of Honk Kong.

Madous, G. F. (1988). The Influence of Testing on the Curriculum. In L. N. Tanner (Ed.), Critical Issues in Curriculum. Chicago: University of Chicago Press.

Menken, K. (2008). High-Stakes Testes as De Facto Language Education Policies. In N. H. Hornberger (Ed.), Encyclopedia of Language and Education (2nd ed.). Springer. https://doi.org/10.1007/978-0-387-30424-3_189

\section{Notes}

Note 1. 'High-quality education', as a comprehensive term, has been since its early use in Tomorrow's schools (1995) the subject of much discussion and heated debates among educators. Any attempt to give a valid definition to 'high-quality education' would distort its nature and therefore would be too vague and over-simplistic. It is an elusive term. Green (1980, p. 120) ironically yet illustratively defines it with reference to the "education that the rich provide for their sons".

Note 2. A standardized test, as its name implies, is an exam which has been devised from tryouts and experimentation for the sake of reliability and validity. It is also a test for which norms have been established and it provides uniform procedures for administering (time limits, response format, and number of questions) and for scoring the test. "Standardized tests are often used by school systems for high-stakes decision making" (Menken, 2008, p. 402).

Note 3. High-stakes exams are so important in the eyes of many stakeholders in the sense that their results, as Madaus $(1988$, p. 87) notes "are seen, rightly or wrongly, by students, teachers, administrators, parents, or the general public, as being used to make important decisions that immediately and directly affect them."

Note 4. Tests are frequently used as a means to engineer innovation, to steer and to guide the curriculum (Alderson, 2004). Tests are, all too often, intended as levers for change (Pearson, 1988). The challenge resides in how to make such mechanism consolidate and reinforce the teaching and learning of skills that are conducive to a betterment of the education system at large.

Note 5. In the mind of many applied linguists, educators and teachers 'item teaching', 'curriculum teaching' and 'teaching-to-the-test' are all too often used interchangeably.

Note 6. Portfolios are collections of various assignments that students have compiled over a period of time, a term, a semester or an academic year. From a pedagogical standpoint, a portfolio denotes "a purposeful collection of any aspect of the students' work which is kept in a file folder, box, ... that tells about the students' improvement, progress, and achievement" (Javanmard and Farahani, 2012, p. 53). Unlike the traditional assessment procedures, portfolio assessment enables learners to actively participate in the evaluation process of their own work (learner-centred assessment).

Note 7. Much has been written about the influence of testing on teaching and learning. "Public examinations influence the attitudes, behaviours, and motivation of teachers, learners and parents, and because examinations often come at the end of a course, this influence is seen working in a backward direction, hence the term, washback.

\section{Copyrights}

Copyright for this article is retained by the author, with first publication rights granted to the journal.

This is an open-access article distributed under the terms and conditions of the Creative Commons Attribution license (http://creativecommons.org/licenses/by/4.0/). 